\title{
Statistical Analysis of Silicon Grease Coated Bushings Characteristics Under Various Contaminated Conditions
}

\author{
N. B. Prakash, G. Shiny, G. Kannayeram, R. Madavan
}

\begin{abstract}
The contamination seriousness level in the working condition of transformers turns into the most critical factor in deciding the protection level of bushings. Flashover because of contamination on bushings makes a noteworthy danger the unwavering quality of the transformers and power framework arrange as well. In order to reduce the pollution flashover of bushings, the silicon grease coating is applied on the surface of bushings. Then, silicon grease coated and non-coated the bushings are polluted with Nacl and Kaolin blend using brushing method. After dried, breakdown voltage of polluted bushings is measured as per standard and the statistical analysis has been carried out to understand the performance of bushings under polluted environment.
\end{abstract}

Keywords: Bushings, breakdown voltage, silicon grease coating, pollution and statistical analysis.

\section{INTRODUCTION}

Flashover on bushings due to the contaminants accumulated on the surface poses a hazard to the reliability of power system network. Bushings are utilized to conduct the electrical energy through enclosures of an electrical apparatus like transformers, circuit breakers, power capacitors and shunt reactors. Failures in these bushings caused due to pollution flashover, loosening of conductors, insulation failure, insulation deterioration due to oxidation and inadequate or improper maintenance [1]. The failure of bushings causes, loss of income, increase in outage time, cost of finance for repairing and have severe effects on the operation of power system network [2]. From the transformer failure analysis, around $10 \%$ of failures in transformers are caused by damages or breakdown in bushings which consecutively leads to catastrophic failures [3].

In general, bushings are made up of porcelain material, perform excellently and defy environmental aging [4]. Notwithstanding that, it has better mechanical quality and brilliant opposition than material debasement brought about by electrical anxieties and releases. Be that as it may, it endures because of hydrophilic surface properties i.e., water can without much of a stretch structure a constant conductive film along the creepage way and subsequently permits surface spillage ebb and flow course through wetted surface. These current forms dry bands on the surface of the bushings, which ultimately cause surface arcing and

Revised Manuscript Received on 14 August, 2019.

N.B.Prakash, Corresponding author Department of EEE, National Engineering College, Kovilpatti, Tamilnadu, India. (Email: nbprakas@gmail.com)

G.Shiny, Department of EEE, Thamirabharani Engineering College, Tirunelveli, Tamilnadu, India.

G.Kannayeram, Department of EEE, National Engineering College, Kovilpatti, Tamilnadu, India.

R.Madavan, Department of EEE, P.S.R Engineering College, Sivakasi, Tamilnadu, India. frequently causes flashover on the surface of the bushings [5].

The deterioration rate of performance of bushing is subjected to where they exposed to contaminate. Industrial waste, coastal salt, natural waste etc... deposits on the surface of the bushings, forms dry pollution layer and operation of the bushings does not affected. Rain drops, relative humidity etc... converts the dry pollution layer into wet, this increases leakage current, resistivity of the pollution layer gets decreased and leads to flashover on the surface of bushings [5]. Flashover of a bushing brings about loss of intensity supply and it might prompts harm to the hardware and devastation of the bushing itself. Contamination type and its seriousness are subject to the air in which bushings are placed into administration. In this foundation of contamination impacts, downpour can have a characteristic washing impact by expelling the contamination layer before it has aggregated to a basic level [6].

In order to improve the performance of bushings under polluted conditions, diminish surface leakage current and cut down the flashover occurrence on existing and installed bushings coatings are used [7]. This training is especially reasonable for bushings introduced at substations with contamination seriousness. To enhance the hydrophobic surface properties of bushings protective coatings are applied. This coating is for inhibiting the formation of dry band formation. Various coatings had been utilized in earthenware bushings like paints, polishes, waxes and varnishes. However, their use is confined as a result of worries over their long haul execution. These coating can easily be wet out as like as porcelain insulators and there will be a chance to damage by corona discharges [8]. Notwithstanding that, when presented to natural anxieties like corona releases and UV, these coatings are easily loss hydrophobicity. For getting higher hydrophobicity, to reduce the formation of dry band layer, to reduce the leakage current flow and to reduce the deterioration in bushings performance silicon greases are used for coating [9].Greases have been an accepted method and for minimizing contamination flashover. Silicone greases are composed of fumed silica and oil. Silicon greases maintains the viscosity with the hotness of $-50 \mathrm{oC}$ to $+200 \mathrm{oC}$ and won't dissolve since it can be used under all climate conditions [10]. 


\section{STATISTICAL ANALYSIS OF SILICON GREASE COATED BUSHINGS CHARACTERISTICS UNDER VARIOUS CONTAMINATED CONDITIONS}

Weibull distribution statistics technique is the universally admitted and successful technique used for mathematical modeling to forecast the failure rate of any apparatus using bathtub curve [11]. The failure rate of engineering products is not constant with respect to time. A bathtub curve is a universally valid technique to examine the failure probability of a product and it's classified into three stages [12]. Early, random and wear out failure stage. In early failure stage, fabrication and installation errors or defects in the apparatus causes failure. In random stage, failure rate is low and stable and in wear out stage, failure rate increases with respect to aging. This wear out stage pointed out the equipments end of life and hence preventive alternate is necessary [13]. This work investigates the performance of bushings with and without varnishing and evaluates its leakage current control and its flashover voltage in various pollution severity levels.

\section{TEST EQUIPMENT, SPECIMENS AND PROCEDURES}

\subsection{Test Equipment}

The artificial pollution tests have been carried out in an artificial climate chamber. The test power is supplied with $100 \mathrm{kV}$ test transformer. Both the AC and DC supply can be supplied for the pollution tests. In this work, the pollution tests have been carried using AC supply alone. The chamber made up of transparent fiber glass container. The test setup having coupling capacitance, high voltage tests transformer, and artificial climate chamber. The rated voltage of the transformer is $2 \times 0.22 / 100 / 0.22 \mathrm{kV}$, rated current $2 \times 22.8 /$ $0.1 \mathrm{~A}$, rated output is $10 \mathrm{kVA}$. The test power supply satisfies the requirement recommended by IEC 60507.

\subsection{Sample preparation}

Prior to start the pollution performance test, bushings are cleaned carefully with distilled water so that the fine dusts and old greases are removed from the surface. Then, the test samples are dried naturally under sunlight. Consecutively, silicon grease is applied on the surface of the bushings uniformly by using brushing or spraying methods [14].

The silicon grease coated bushings are polluted with different ratio using brushing method. Here, Nacl and kaolin are used as polluting agents. By blending the Nacl and kaolin at various combinations pollution samples are prepared and applied on the surface of the bushings as shown in Table 1. After applying pollution on the surface, the bushings are allowed to dry before the conduction of pollution performance test. The degree of pollution severity of soluble agents is measured using ESDD.

After the completion of BDV test, the polluted bushings are dried under sunlight and dried $\mathrm{Nacl}$ and kaolin are collected from the surface of the bushings separately. The collected samples are dissolved in $100 \mathrm{ml}$ of distilled water and the conductivity of the salt samples using conductivity measuring instrument.
Table 1: ESDD values for different pollution levels

\begin{tabular}{|c|c|c|}
\hline $\begin{array}{c}\text { Amount of Nacl } \\
\text { (gm) }\end{array}$ & $\begin{array}{c}\text { Amount of kaolin } \\
\text { (gm) }\end{array}$ & ESDD \\
\hline 20 & - & 0.0063 \\
\hline 20 & 4 & 0.0232 \\
\hline 20 & 8 & 0.0928 \\
\hline 20 & 12 & 0.3796 \\
\hline
\end{tabular}

\section{EXPERIMENTAL DESCRIPTION}

The breakdown voltage of bushings is measured as per the standard. The polluted non-coated and coated bushings are placed inside the artificial climate chamber. A step input voltage is applied on the bushings and at a particular voltage breakdown occurs and this voltage is called as breakdown voltage. This measurement is carried out with 20 breakdown voltage data for acquiring the distribution scattering. Between each measurements 15 minutes of time interval is provided to avoid early breakdown due to the ionized are around the bushing.

Table 2: Statistical data of breakdown voltage of bushings for various ESDD.

\begin{tabular}{|l|l|l|l|l|l|l|l|}
\hline \multirow{2}{*}{ ESDD } & Type & $\begin{array}{l}\text { Mean } \\
\text { BDV } \\
(\mathbf{k V )}\end{array}$ & $\begin{array}{l}\text { Standard } \\
\text { Deviation } \\
(\mathbf{k V})\end{array}$ & Skewness & Kurtosis & $\begin{array}{l}\text { Minimum } \\
\text { BDV (kV) }\end{array}$ & $\begin{array}{l}\text { Maximum } \\
\text { BDV (kV) }\end{array}$ \\
\hline \multirow{2}{*}{0.0063} & $\begin{array}{l}\text { Non- } \\
\text { coated }\end{array}$ & 60.89 & 1.075 & 0.045 & -1.285 & 59.2 & 62.5 \\
\cline { 2 - 8 } & Coated & 67.59 & 1.33 & -0.160 & -0.795 & 65 & 69.50 \\
\hline \multirow{2}{*}{0.0232} & $\begin{array}{l}\text { Non- } \\
\text { coated }\end{array}$ & 56.83 & 1.42 & -0.021 & -0.228 & 54.2 & 59.7 \\
\cline { 2 - 8 } & Coated & 64.22 & 2.057 & -0.486 & -0.825 & 60.5 & 67.4 \\
\hline \multirow{2}{*}{0.0928} & $\begin{array}{l}\text { Non- } \\
\text { coated }\end{array}$ & 50.45 & 2.006 & -0.071 & -0.507 & 47.2 & 54 \\
\cline { 2 - 8 } & Coated & 55.55 & 1.742 & -0.052 & -0.482 & 52.3 & 59.1 \\
\hline \multirow{2}{*}{0.3796} & $\begin{array}{l}\text { Non- } \\
\text { coated }\end{array}$ & 42.21 & 2.109 & -0.301 & -0.006 & 37.6 & 46.1 \\
\cline { 2 - 8 } & Coated & 48.61 & 2.045 & -0.288 & -0.003 & 44 & 52.5 \\
\hline
\end{tabular}

Histogram of breakdown voltage of bushings with various ESDD levels are obtained from the data collected through the experiments mentioned early and shown in Fig. 1-4. From the histogram, various parameters like mean, standard deviation, skewness, kurtosis, and maximum and minimum values are determined for analysis.

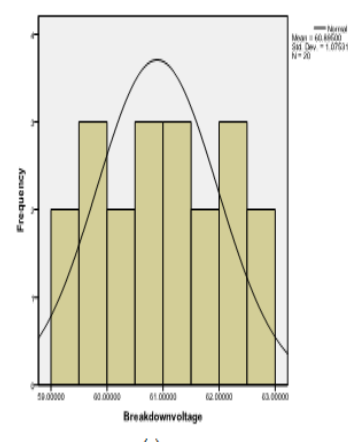

(a)

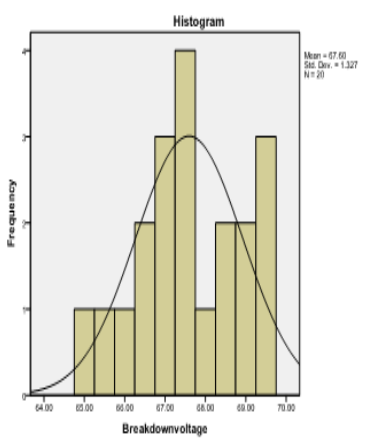

(b)
Fig.1: Breakdown voltage of $11 \mathrm{kV}$ bushing with ESDD 0.0063 (a) Non-coated and (b) Coated 


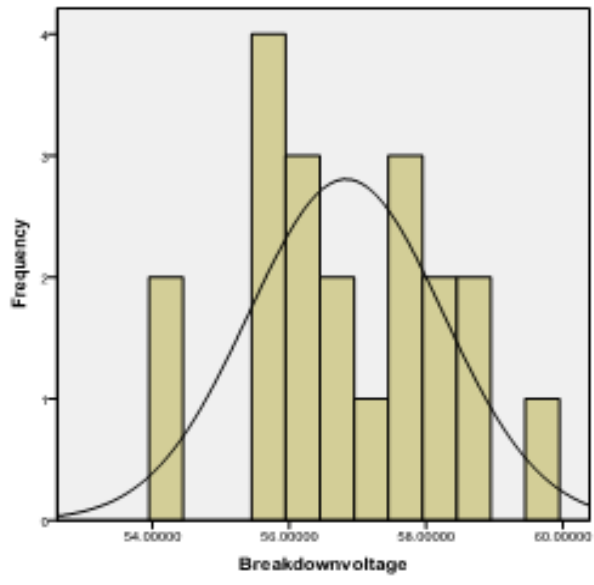

(a)

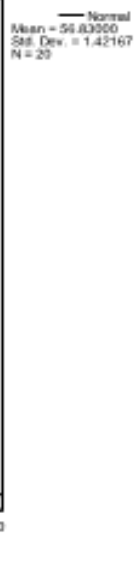

Fig.2: Breakdown voltage of $11 \mathrm{kV}$ bushing with ESDD 0.0232 (a) Non-coated and (b) Coated

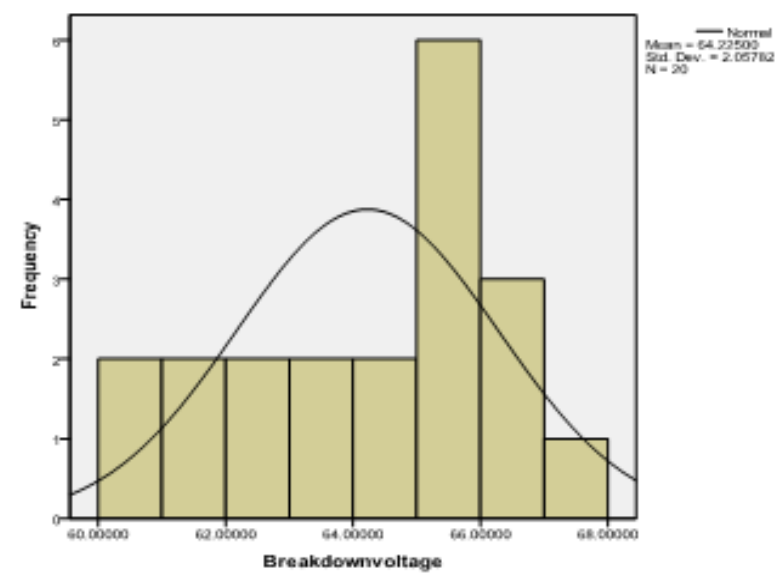

(b)

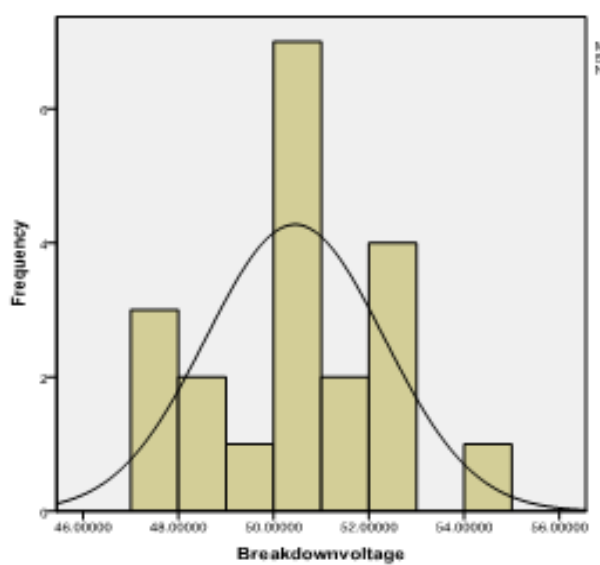

(a)

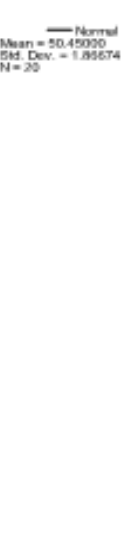

(b)

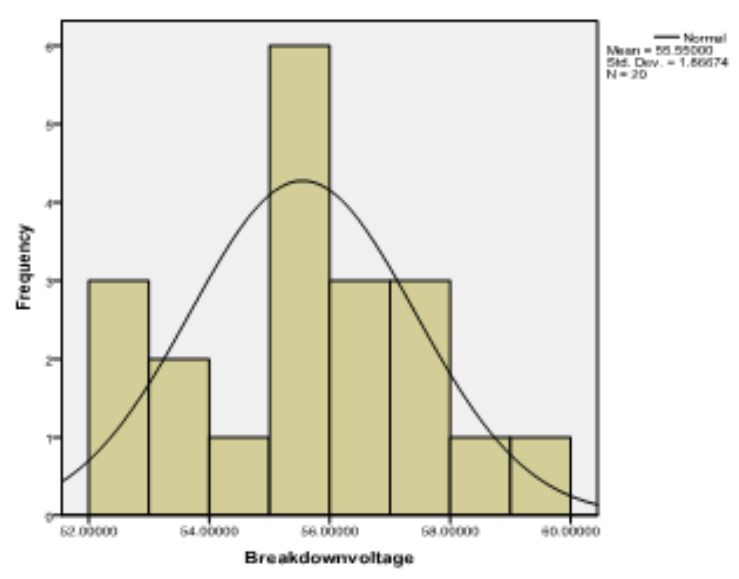

Fig.3: Breakdown voltage of $11 \mathrm{kV}$ bushing with ESDD 0.0928 (a) Non-coated and (b) Coated

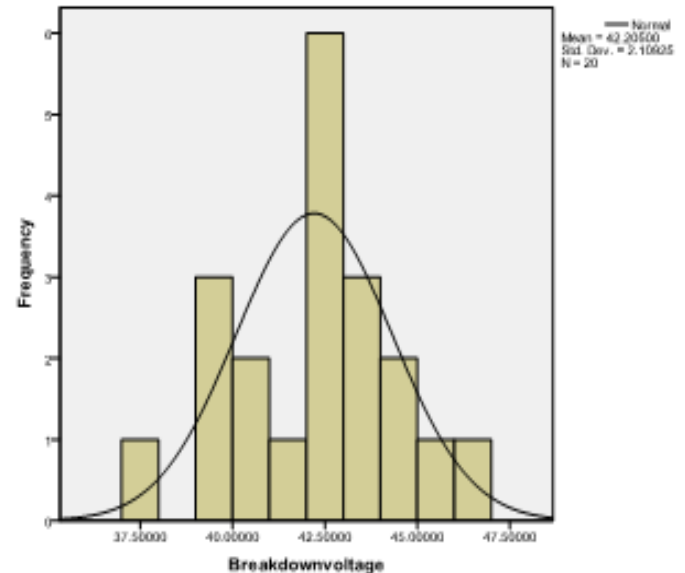

(a)

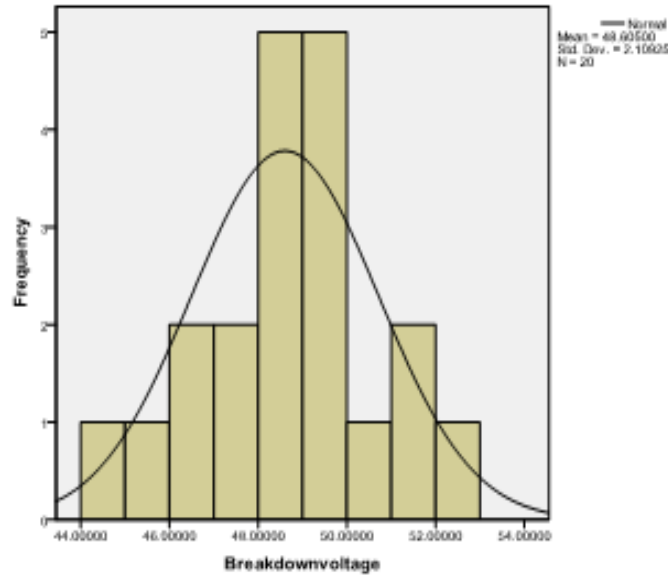

(b)

Fig.4: Breakdown voltage of $11 \mathrm{kV}$ bushing with ESDD 0.3796 (a) Non-coated and (b) Coated

By looking over Table 2, it's inferred that, mean BDV of non-coated bushings have lesser BDV compared to silicon grease coated bushings and the standard deviation is also with the limit. It clearly shows that, silicon grease coated bushings performed well in polluted environment by vanquishing the spillage current and decreasing the dispersal over the outside of the bushing. The adequacy of the oil covering is relies upon number of variables, for example, covering thickness, uniformity, contamination harshness.
With the increase in pollution level (ESDD values) BDV of all the bushings gets reduced. The increased ESDD values increases the leakage current, thereby surface conductivity of the bushings gets increased.

Published By: Blue Eyes Intelligence Engineering \& Sciences Publication 


\section{STATISTICAL ANALYSIS OF SILICON GREASE COATED BUSHINGS CHARACTERISTICS UNDER VARIOUS CONTAMINATED CONDITIONS}

From the histogram, it's able to know that whether the data are symmetric or asymmetric. For this, kurtosis and skewness values are used to determine the position of centre of distribution curve. For normal distribution curve, some assumptions are made; the values of skewness and kurtosis are 0 and 3 respectively. But in practical case it's quite difficult to attain exact normal distribution curve. The experimentally attained skewness and kurtosis values are somewhat closer to the assumed values. Therefore all the bushings almost follow the normal distribution curve.

\section{STATISTICAL ANALYSIS\& RESULTS}

The Weibull distribution plot is drawn between probability of failure and breakdown voltage. At the $63.2 \%$ of failure, breakdown voltage of silicon grease coated bushings is high compared with non-coated bushings.
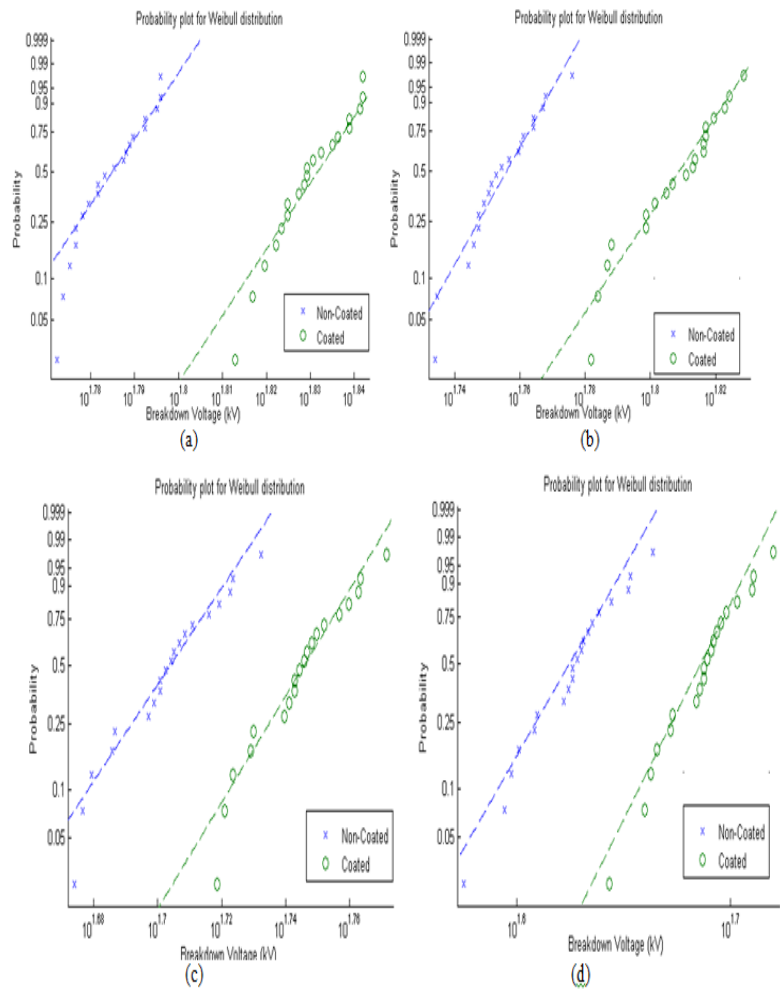

Fig.5: Failure probability of breakdown voltage of bushings with various ESDD

(a) 0.0063 , (b) 0.0232 , (c) 0.0928 and (d) 0.3796

Fig. $5(\mathrm{a}-\mathrm{d})$ shows the Weibull distribution plot, which is used for modeling the distribution. The mean breakdown voltage of coated bushings is higher than non-coated bushings. Moreover, the lowest breakdown voltage of coated bushings is not lower than that of non-coated bushings.

\section{CONCLUSION}

The performance of bushings with pollution is evaluated through extensive experimental examination and statistical analysis. The following conclusions are made from the analysis: From the experimental analysis, it is known that, silicon grease coated bushings performs well compared to non-coated bushings. This is also proven by Weibull analysis. The silicon grease coated bushings have higher breakdown voltage under pollution. With the increase in pollution severity level, breakdown voltage of bushings is decreased. But in silicon grease coated bushings breakdown voltage are in acceptable range. Therefore it's concluded that silicon grease coatings improve the performance of bushings under pollution environment.

\section{REFERENCES}

1. A. Metwally, "Failures, monitoring, and new trends of power transformers," IEEE Potentials, May/June 2011, pp. $36-43$

2. T. McGrail, K. Elkinson, "Asset Management: Power Transformer Fleet Condition Assessment and Risk Management", 2013.

3. CIGRE-WG 12-05: An international survey on failures in large power transformers in service, Electra No. 88 1983, S. 21-48.

4. A.I. Elombo, J.P. Holtzhausen, H.J. Vermeulen, P.J. Pieterse, "Comparitive Evaluation of Leakage current and Aging Performance of HTV SR Insulator of Different Creepage when Length Energised by AC DC+ OR DC-in a Marine Environment", IEEE, vol. 20, no. 2, pp. 421-428, 2007.

5. Chris S. Engelbrecht, Ralf hartings, Helena Tunell, Bjom Engstrom, Harald janssen, "Pollution Test for Coastal Conditions on an $800 \mathrm{Kv}$ bushing", IEEE Transactions on Power Delivery, vol. 18, no. 3, pp. 953-959, 2009.

6. Xiangliang Dong, jianlian hu Jiang, lichun shu, "Artificial Pollution Methods on AC Flashover voltage of Composite insulator", IEEE Transactions on Dielectric and Insulation, vol. 19, no. 2, pp. 714-722, 2012.

7. Gorur, R. S., Cherney, E. A., de Tourrcil, C., DumoraD., Harmon R.,and Hervig H., "Protective coatings for improving contamination performance of outdoor high voltage ceramicinsulators," IEEE Transactions onPower Delivery, Vol. 10, No. 2, 1995.

8. Kim, S. H., Cherney, E. A., and Hackam, R.,"The Loss and Recovery of Hydrophobicity of RTV Silicone Rubber Insulator Coatings," IEEE Trans.PD, Vol. 5, pp. 1491-1499, 1990.

9. Gorur, R. S., Sundhara, S., and Amburgey, O. G.,"Contamination performance of polymericinsulatingmaterialsusedforoutdoorinsulationap plications," IEEE Trans. Electrical Insulation, Vol. 24, No. 4, pp. 713-716, 1989.

10. Deng, H., Hackam, R., and Cherney, E. A., "Influence ofThickness, Substrate type, Amount of Silicone Fluid and Solvent Type on the Electrical Performanceof RTV Silicone Rubber Coatings," IEEE Trans. PD, Vol. 11, pp. 431-443, 1996.

11. Madavan R and S. Balaraman, "'Failure analysis of transformer liquid - solid insulation system under selective environmental conditions using Weibull statistics method', Engineering Failure Analysis, Vol. 65, pp. 26-38, 2016.

12. Robert, B. Abernethy, "The New Weibull Handbook Fifth Edition, Reliability and Statistical Analysis for Predicting Life, Safety, Supportability, Risk, Cost and War-ranty Claims", (536 Oyster Road, North Palm Beach, FL) 2006

13. M. Mirzai, A. Gholami, F. Aminifar, Failures Analysis and Reliability Calculation for Power Transformers, J. Electrical Systems, 2006.

14. NB Prakash, $M$ Parvathavarthini and $R$ Madavan, "Mathematical Modeling on AC Pollution Flashover Performance of Glass and Composite Insulator", Journal of Electrical Engineering Technology, Vol.10, 2015. 